\title{
Getting Profitable CCU off the Ground: Contingent Pathways and Bergen Carbon Solutions
}

\author{
Siddharth Sareen ${ }^{1,2 *}$ and Jan Sagmo ${ }^{3}$ \\ ${ }^{1}$ Department of Geography and Centre for Climate and Energy Transformation, University of Bergen, Bergen, Norway, \\ ${ }^{2}$ Department of Media and Social Sciences, University of Stavanger, Stavanger, Norway, ${ }^{3}$ Bergen Carbon Solutions, Bergen, \\ Norway
}

As carbon capture utilization and storage (CCUS) gains policy traction and pilot project funding, CCS usually gets the limelight, whereas CCU is often overlooked. CCU, if feasible, has two potential advantages: it obviates risks and monitoring needs associated with longterm storage, and it creates economic value to offset carbon capture costs. Yet scholarly accounts of $\mathrm{CCU}$ feasibility are rare. To address this lacuna, the manuscript channels indepth knowledge of a CCU start-up in Norway into a critical analysis of the barriers and

OPEN ACCESS

Edited by:

Anne Mae Gaffney, Idaho National Laboratory (DOE), United States

Reviewed by: Junfeng Wang, Institute of Process Engineering (CAS),

China

Ludo Diels,

Flemish Institute for Technological Research (VITO), Belgium

*Correspondence: Siddharth Sareen siddharth.sareen@uis.no

Specialty section: This article was submitted to Carbon Capture, Storage, and Utilization, a section of the journal Frontiers in Energy Research.

Received: 18 March 2020 Accepted: 23 November 2020

Published: 15 January 2021

Citation:

Sareen S and Sagmo J (2021) Getting Profitable CCU off the Ground: Contingent Pathways and Bergen Carbon Solutions.

Front. Energy Res. 8:541868. doi: 10.3389/fenrg.2020.541868 opportunities for emerging sectoral enterprises. The trajectory of Bergen Carbon Solutions (BCS) during 2016-2019 is mapped by a human geographer along with its founder. We organize enquiry along three axes: (i) access to "soft" capital (this includes knowledge and human resources), (ii) access to "hard" capital (this includes financing and technical approvals), and (iii) navigation of rapid expansion. Under (i), we present and analyze the contextual conditions and contingencies for the emergence of the core value proposition. Under (ii), we detail the networks, processes, and institutional structures through which the enterprise gained its financial basis and was able to test its CCU process. Under (iii), we complement attention to organizational management by highlighting key informal and human factors. We foreground how the emergence of $\mathrm{CCU}$ is a relational process that depends on how actors in a changing field interact and reconfigure themselves. This informs regulatory policies and economic instruments about overlooked contextual issues related to the modulation and feasibility of scalable, profitable CCU.

Keywords: innovation, governance, human geography, energy transitions, contingent pathways, CCU

\section{INTRODUCTION}

As carbon capture utilization and storage (CCUS) gains policy traction and pilot project funding, CCS usually gets the limelight, whereas CCU is often overlooked. The latter-alternatively referred to as carbon dioxide utilization (CDU) - entails converting $\mathrm{CO}_{2}$ to carbon-based products via physical, chemical, and/or biological processes. Both face different challenges after initial carbon capture: CCS involves secure long-term storage which means extra techno-economic tasks; CCU entails handling captured emissions that typically include complex compounds beyond carbon (North and Styring, 2015). Yet CCU, if feasible, has two potential advantages: it obviates risks and monitoring needs associated with long-term storage, and it creates economic value to offset carbon capture costs (Bruhn et al., 2016). The latter potential advantage is critical, as the major barrier to the takeoff of scalable carbon capture technologies is their current lack of economic competitiveness 
(Fernández-Dacosta et al., 2017). Yet scholarly accounts of CCU feasibility are rare at this emergent moment (Jones et al., 2017); hence a case study of getting CCU off the ground is timely and relevant. Moreover, CCUS efforts have largely been promoted by large-scale actors such as fossil fuel companies with an interest in advancing this segment; hence, we know relatively little about bottom-up efforts in this growing sector.

This article seeks to address academic lacunae in this regard by contributing an empirically informed analysis of some of the challenges associated with advancing industrial CCU. Our argument is aimed at contributing insight from a relatively rare and novel perspective within scholarly debates on expanding CCUS. It channels in-depth knowledge of a CCU start-up into a critical analysis of the barriers and opportunities for emerging enterprises in this under-researched sector. By 2020, Bergen Carbon Solutions in Norway had secured over 1.6 million USD in grants and venture capital within four years of being established. Its trajectory during this period is mapped by a human geographer along with its founder, based on these methods: three intensive 1.5-3 h long conversations that drew on BCS's practical experience; analysis of firm documents including internal ones; consultation of relevant thematic peerreviewed scholarship; and a knowledge co-production approach to writing this article, over the course of eight months.

We organize enquiry along three axes: 1) access to "soft" capital (this includes knowledge and human resources), 2) access to "hard" capital (this includes financing and technical approval), and 3) navigation of rapid expansion. These emerged through an abductive approach, where we examined our case to identify understudied factors in extant scholarship on CCU and developed a strategy to explain them as best possible. The resulting axes systematize and structure our narrative. The summary of each axis below emphasizes our analytical approach and the scope of this study.

- Access to soft capital: emerging technological niches require capacity-building and re-skilling of human resources and sufficient access to cutting-edge knowledge (cf. Haerens, 2017), in order to achieve the so-called breakthrough by keeping pace with global developments and becoming competitive within sectoral regimes and landscapes.

- Access to hard capital: sustaining technological niches requires adjustment of funding to ensure adequate support mechanisms (Falcone and Hiete, 2019), in order to create a stable innovation ecosystem with economic opportunities for industrial entrepreneurship.

- Navigation of rapid expansion: to complement organizational and financial management, rapid expansion of a technological niche requires coordination among networked actors that can ensure responsive innovation (Stephens and Scott, 2010). This implies a need for adaptive relations between industrial and policy arenas (Haarstad and Rusten, 2016).

By tracing the emergence of our case in terms of these three factors below, we highlight how human geography perspectives can guide the development of regulatory and economic mechanisms. These go beyond simply financial incentives and penalties and concern the coordinated enablement of a stable innovation ecosystem to advance an emerging technological niche. Attention to intra-organizational management, financial sustainability, and networked governance can support roll-out of $\mathrm{CCU}$ in a manner that situates technical feasibility within societal contexts.

\section{KEY FACTORS: ACCESS TO SOFT CAPITAL, ACCESS TO HARD CAPITAL, AND NAVIGATING RAPID EXPANSION}

This section reports on and analyzes the case of Bergen Carbon Solutions (BCS) along these axes.

\section{Access to Soft Capital}

To examine access to soft capital, we present and analyze the institutional conditions and social contingencies for the emergence of the initial core value proposition of BCS-the process of converting carbon dioxide to carbon nanofibers. Higher grades of this product are valued at up to 500 USD per kilogram. The narrative is unpacked with a focus on uncertainty, risk, human factors, and various support mechanisms linked with access to knowledge and human resources. In drawing out the contingencies of the pathway BCS took, we reflect on what enabled and constrained this.

In 2016, the founders were students at Bergen University College (now Western Norway University of Applied Sciences). They both wrote Bachelor theses on the production of nanocarbon from ambient air. This led to the Norwegian Engineering and Technology Organization's "NITO-award" as well as an environmental award. On this basis, BCS was established. This signals the importance of early recognition mechanisms, which are amply present in Norway's technical knowledge-industrial complex (cf. Klitkou and Kaloudis, 2007; Aslesen and Freel, 2012).

The company was initially located at a local incubation unit in Bergen. Early on, getting approval from mentors and investors in Bergen proved to be quite a struggle. This led the founders to apply for seed funding for regional innovation (VRI) from a VRI Fund in Norway, which yielded 100,000 NOK (approximately 10,500 USD) to pilot a test project. This pilot aimed to develop a process for carbon nanofiber production from $\mathrm{CO}_{2}$, through chemical electrolysis. The pilot used $\mathrm{CO}_{2}$ sourced from gas emissions. BCS chose a research lab with an established reputation in Europe and located in Norway, namely, SINTEF (Organization for Industrial and Technical Research, in Norway). These early choices demonstrate their keenness to combine product innovation capability with reputational resources (cf. O'Cass and Sok, 2014). SINTEF followed the same procedure to conduct tests as the BCS founders.

The replicated results this project produced were sufficiently convincing for BCS to gain the confidence of investors and others with industry knowledge and established presence in this segment of the energy sector. At this point, human capital was another key requisite input. The founders followed a mixed strategy to recruit employees with pertinent skills. For instance, an early intern, who was an immigrant whose talents were being insufficiently utilized in 
Norway, proved her competence and transitioned into an employee role. A funding application to the public agency Enova included the profiles of six initial employees with relevant skills as an important bulwark against possible skepticism about the ability of a new entrant with an emerging technology. Thus, human resource management was also instrumental to financial success.

\section{Access to Hard Capital}

To analyze access to hard capital, we detail the networks, processes, and institutional structures through which BCS gained the financial wherewithal to become a player in an emerging sector without an established economic basis. We also explain the process through which it acquired the approval to test out its CCU process. The emphasis here is on various bureaucratic and technocratic requirements, as well as on addressing a key concern in relation to CCUS-how can actors establish a sufficient basis for society to champion (and, importantly, invest in) specific pathways within what has till recently been considered a contentious sector characterized by lack of evidence?

Once the SINTEF pilot had confirmed the replicability of results, the founder's alma mater, Vestland University College, provided crucial support at this still relatively early stage. This spared BCS the need to invest considerable further time and effort in becoming a financially self-sustaining company, an important advantage in a rapidly evolving niche (Cooke 2002). This was critical in enabling rapid scale-up for BCS, which in turn positioned it to attract hard capital (cf. Selig, 2014).

The first time that BCS raised funding from investors was in March 2017. This included 1 million NOK (approximately 105,000 USD) from private investors and 1.5 million NOK (approximately 160,000 USD) from Innovation Norway, the national innovation agency. This sum of 265,000 USD enabled BCS to manufacture a prototype that converted $\mathrm{CO}_{2}$ to carbon nanofibers. This entailed the combination of competencies in electrolysis and nanoscience. Without disclosing proprietary details, suffice it to say that the prototype yielded carbon nanofibers, within principle continuous substrate recovery. BCS opted to work with the company Goodtech and succeeded in manufacturing this prototype in the form of a closed production unit. Conventional methods of producing a kilogram of carbon nanofibers require approximately 1,400 kilowatt hour (kWh) energy using chemical vapor deposition and approximately $1,800 \mathrm{kWh}$ using electron spinning. The CCU method employed by BCS is far less energy intensive: it has achieved $50 \mathrm{kWh}$ per kilogram of nanofibers, with scope to further improve efficiency.

After a half-year delay, the prototype was complete by summer 2018, and BCS was poised to begin a test period of operation. An industrial investor bought into the company, enabling a new test ("emission" in industrial parlance) during autumn 2018. This test gave BCS the proof of concept it required to continue its growth, toward building an industrial scale operation. This is another instance of a support mechanism the Norwegian ecosystem (others include Scottish and Canadian ones) excels in providing, namely, bridge financing to make up demand-side funding gaps during early stages in order to increase project attractiveness for private investors prior to industrial-scale project finance (Rasmussen and Sørheim, 2012).

For the next phase, BCS decided to hire additional employees. The next larger (with an extended period of emissions) test was conducted in January 2019, supported by 1.6 million USD secured in private investment. On this basis, and despite discouraging counsel from an experienced industry expert, BCS applied to the Norwegian public agency Enova. This led to BCS securing the equivalent of 1.3 million USD in soft funding to engineer a scaledup carbon nanofiber manufacturing module located on-site at a solid waste incineration facility comprising Bergen's largest point source of carbon emissions. ${ }^{\text {a }}$ This phase aimed to demonstrate the feasibility of running the process in real-world conditions. For the purpose and scope of this article, we cap the narrative of access to hard capital at this stage of the continuing process. However, to indicate potential future impact, it is worth noting that the next aim is to link up with other companies that have on-site emissions. BCS is developing competence in optimizing the closed production unit for specific on-site applications as well as for carbon nanofiber recovery. This would generate twin revenue streams from company payments for carbon capture as well as carbon nanofiber sale.

\section{Navigation of Rapid Expansion}

Finally, we turn to the navigation of BCS's rapid expansion. While informed by the organizational management and administration scholarship that is drawn upon in this article, our analysis additionally underscores the informal factors and individual human agency that played an outsize role in the early years of this rapidly growing company (cf. Collins and Morten, 2011; Trevor-Roberts, 2006), in an emerging sector characterized by many risks. The account is oriented toward deconstructing the difficult tradeoffs and the role of luck that feature in such contexts of organizational expansion, partly despite and partly due to high uncertainty. We seek to transcend a success-failure binary and foreground how the emergence of CCU is a relational process (Bouzarovski and Haarstad, 2019); that is, it depends on how actors in a changing field interact and reconfigure themselves.

The narrative captured by the two axes above foregrounds the operational and managerial challenges of BCS during 2016-2019. Yet, detailed knowledge of the inner workings of the company enables us to complement and enrich this otherwise neat account with some messy details. The main element we highlight here is the unexpected challenges that come with the uncertainty of rapid expansion of small, emerging actors in a changing sector. Unlike a large and established company, scaling start-ups remain relatively nimble and adaptive, but they also have a lower margin for error and failures that might test the patience and faith of investors they rely upon (Aernoudt, 2017). For BCS, despite repeated technoeconomic successes and growth, risk expressed itself in a more personal form. Its CEO, in the midst of a sustained growth phase,

${ }^{a}$ For coverage in Norway, see https://www.naturpress.no/2019/01/10/i-bergenskal-co2-fanges-og-bli-til-karbon-nanofiber/.

${ }^{\text {bSee }}$ public details at https://www.enova.no/om-enova/om-organisasjonen/ teknologiportefoljen/produksjon-av-karbon-nanofiber-med-utgangspunkt-i-co2fra-roykgass/. Also see the BCS website: https://bergencarbonsolutions.com. 
encountered several health issues that required multiple surgeries and bedrest. Besides a managerial and leadership role, BCS was dependent upon his presence for key meetings, such as with investors abroad, which were especially challenging given the personal and time-sensitive nature of such business negotiations (cf. Liao and Welsch, 2003). The navigation of such stress factors, while not evident in its formal funding proposals, was nevertheless vital for BCS to maintain its upward trajectory. It is a largely overlooked factor in extant thematic literature.

An additional personal factor that highlights human agency as a dynamic driver was this CEO's decision to enroll in a postgraduate degree focused on knowledge management. He judged this to be a step forward in rounding out his chemistry and other versatile training and work experience for the new role he found himself in at the helm of a growing CCU enterprise. Such choices inevitably come with tradeoffs given the time constraints associated with leadership positions, so it can be read in multiple ways, for example, as a forward-looking move that shows commitment to scaling, or as a risky decision prioritizing personal growth during a demanding period for BCS. Rather than making a normative statement, our intent with flagging this point is to instantiate the very human and personal drivers that constitute part of the basis behind entrepreneurial trajectories. Considerable scholarship on entrepreneurship does focus on social capital (e.g., Pathak and Muralidharan, 2016), personality traits, and networks beyond the professional matter, including personal characteristics of leaders and their domestic circumstances.

As a final, more socio-technical aspect of navigating rapid expansion, we return to BCS's trajectory after expanded support in 2019. This led to an agreement with BIR, a solid waste management company, who partnered with BCS to locate its new module at BIR's waste management plant in Bergen. The aim was to use the flue gas from the chimney to produce carbon nanofibers, starting in 2020. This is an example of the sourcereceiving matching that researchers have recommended (Patricio et al., 2017). At a trans-local scale, BCS is aware of significant interest for its technical innovation and offering in China and is developing an ambitious near-future expansion strategy. Norway is a world-leading context for such technological development, notable both through its September 2020 announcement of the massive CCS project Longship worth over $€ 200$ million $^{c}$ and through sustained media coverage and public interest in future CCU possibilities linked with BCS. ${ }^{\mathrm{d}}$ The world's largest and most

${ }^{c}$ For the official announcement and Government White Paper, see https://www. regjeringen.no/en/aktuelt/the-government-launches-longship-for-carboncapture-and-storage-in-norway/id2765288/.

${ }^{\mathrm{d} S}$ See coverage from the establishment of BCS in 2016 (https://www.tu.no/artikler/ studenter-vil-lage-karbon-nanofiber-av-co2/359380), a prize nomination in 2017 (https://energiogklima.no/spirprisen/spir-kandidat-bergen-carbon-solutions-as/), expansion in 2019 (https://shifter.no/bergen-carbon-solutions-finn-blydtsvendsen-jan-borge-sagmo/manelanding-i-vest-grnderne-som-gjor-gull-avklimagass-oker-farten/121411), and national discussion about carbon nanofiber (https://www.nrk.no/vestland/forskarar-fryktar-at-_supermateriale_-gir-likhelserisiko-som-asbest-1.14403895) and the City of Rotterdam Challenge pilot award in 2020 (https://rotterdamunlocked.com/2020/09/24/unlocked-lays-thegroundwork-for-rotterdams-circular-vision-for-the-future/). flexible carbon capture testing facility, Technology Centre Mongstad, has allocated space to BCS to use their CO2 feedstock for carbon nanofiber production. The $\mathrm{CO}_{2}$ does not require cleaning, but its $\mathrm{H}_{2} \mathrm{O}$ content needs to be reduced. BCS has scheduled large-scale testing of this for late 2021.

\section{PRACTICAL IMPLICATIONS AND FUTURE RESEARCH NEEDS}

To ensure broad readership, this article eschews theoretical debates at highly abstract levels within particular domains such as sustainability transitions or organizational management. Instead, this concluding discussion links to practical considerations and possibilities. This arguably unique contribution in the early days of CCU provides pointers to orient future studies, building on recent reviews (such as Jones et al., 2017) through novel empirical analysis. The combination of a trained scholar and deeply knowledgeable practitioner ensures rigorous, ethical, and critically informed insights on the contingent pathways of CCU technologies at a timely juncture.

Within the research topic "Emerging Technologies and Associated Scientific Advancements for CCUS Deployment," our contribution has implications for regulatory policies and economic instruments, as well as overlooked, more informal contextual issues related to the feasibility of scalable, profitable CCU solutions. With global competition emerging, BCS expects to have a functional project on the market by 2023 . Hence, an understanding of the factors that led to its emergence is key for developing appropriate policies to modulate multiple upscaling processes.

Three sets of key takeaways stem from the three axes identified and operationalized above.

Access to soft capital: this axis helped to identify the vital role played by the highly developed industrial innovation ecosystem in Norway. From its incipient stage, the core technology behind BCS received sufficient support for research and development. It was thus possible to transition rapidly through steps such as replication of results in world-class laboratory settings, proof-ofconcept testing, bigger pilots, and scaling up the prototype development with an industrial partner-the solid waste management company BIR-to set up a real-world project targeting completion in 2020. These developments highlight the key supportive role played by knowledge institutions like applied universities (Cooke, 2002), industrial organizations that recognize promising projects (Klitkou and Kaloudis, 2007; Aslesen and Freel, 2012), and the availability of financing mechanisms through public agencies and private investors at early stages preceding technological readiness (Selig, 2014; Haerens, 2017). Soft capital remained important even once the scaling process was well underway, as evident in the case of the ENOVA support that BCS secured.

Access to hard capital: this axis aided the analysis of BCS's trajectory once it had moved to the proof-of-concept stage. Rather than being a single definitive moment of securing funding, the case shows the iterative nature of financing required to successfully complete each step during this growth 
phase (cf. Aernoudt, 2017). Arguably, clarity of vision was key in order for BCS to chart its course (North and Styring, 2015; Falcone and Hiete, 2019), as demonstrated in submitting a funding application to ENOVA despite counsel to the contrary. But the very presence of such public agencies and options is a critical factor, and Norway is one of a handful of countries that provide a sufficient set of complementary factors for a robust scale-up process (O'Cass and Sok, 2014; Rasmussen and Sørheim, 2012).

Navigation of rapid expansion: finally, this axis brought to the fore the importance of informal and personal factors, as well as networked governance, for BCS to navigate rapid expansion and the diverse challenges that it poses. The personality and personal circumstances of leaders like the CEO, the willingness to embrace uncertainty, and the effects of uncertainty on decision-making (cf. Liao and Welsch, 2003; Trevor-Roberts, 2006) emerge as crucial factors toward a holistic grasp of how firms like BCS, which deal with dynamic technological niches, grow in an evolving sector. At the same time, the importance of social capital and actor networks cannot be discounted (Pathak and Muralidharan, 2016), with the matching of a source like BIR and a receiver like BCS being a case in point to engender potential strong regional growth of CCU (cf. Patricio et al., 2017). The relatively understudied nature of such aspects in extant scholarship underscores the relevance of this axis, which applies a relational approach (cf. Bouzarovski and Haarstad, 2019) to dynamics of change.

To conclude on a practical note, we situate the relevance of our analysis within current trends in the emerging technological niche that is CCU. So far, CCU plants are few in number and largely limited to small-scale pilots. Yet, the segment is of interest to big players-such as large fossil fuel companies-and characterized by their presence. This implies that small emerging enterprises like BCS face a sectoral political economy that does not favor them. They struggle to get buy-in from large companies that have already thrown their financial weight behind CCS for several years. Rather, actors like BCS find synergies with clients that have a carbon emissions issue that BCS is likely to be able to resolve profitably or with lower costs through CCU, as in the case of BIR. Given that such clients are plentiful, innovation ecosystems that support the emergence of technological niches and scaling processes are likely to leave regions such as Bergen and actors such as BCS in a good position

\section{REFERENCES}

Aernoudt, R. (2017). Executive Forum: the scale-up gap: and how to address it. Ventur. Cap. 19 (4), 361-372. doi:10.1080/13691066.2017.1348724

Aslesen, H. W., and Freel, M. (2012). Industrial knowledge bases as drivers of open innovation? Ind. Innovat. 19 (7), 563-584. doi:10.1080/13662716. 2012.726807

Bouzarovski, S., and Haarstad, H. (2019). Rescaling low-carbon transformations: towards a relational ontology. Trans. Inst. Br. Geogr. 44 (2), 256-269. doi:10. $1111 / \operatorname{tran} .12275$

Bruhn, T., Naims, H., and Olfe-Kräutlein, B. (2016). Separating the debate on CO2 utilisation from carbon capture and storage. Environ. Sci. Pol. 60, 38-43. doi:10. 1016/j.envsci.2016.03.001 to be competitive if such technologies hit market readiness in the near future.

For BCS, the potential expansion of applications of carbon nanofibers is a matter of commercial interest. For instance, technological innovation with lithium ion batteries that include carbon nanofibers (Kwon et al., 2018a; Kwon et al., 2018b; also see Shi et al., 2017) could herald demand and price increases for their product, as energy storage batteries proliferate as part of low-carbon energy transitions. While the current stage of development does not allow certainty, BCS's success so far has been premised on rapid readiness for precisely such sectoral shifts and on having the deepest experience with its core technological proposition. The three axes we put forward and demonstrate using this case provide insight into these dynamics and relatively neglected choices by actors. They can enable policymakers and practitioners to articulate a more comprehensive and nuanced set of mechanisms that facilitate the prospective emergence of CCU as a breakthrough niche and treat innovative enterprises in line with evolving energy sector concerns and priorities.

\section{DATA AVAILABILITY STATEMENT}

The datasets for this article are not publicly available because they include qualitative research on sensitive and proprietary data. Requests to access the datasets should be directed to Siddharth Sareen, Siddharth.Sareen@uib.no.

\section{AUTHOR CONTRIBUTIONS}

SS led the conceptualization, framing, and writing. JS led data reporting. Both authors contributed to all aspects of the paper.

\section{FUNDING}

The authors are grateful for funding from the University of Bergen-Equinor Akademia Agreement (project "Energy Transitions") and the Trond Mohn Foundation (project "European cities as actors in climate and energy transformation," grant BFS2016REK04).

Collins, J., and Morten, T. (2011). Hansen. Great by Choice: uncertainty, Chaos and Luck: Why some thrive despite them all. London: Random House, 320.

Cooke, P. (2002). Knowledge economies: clusters, learning and cooperative advantage. London and New York: Routledge, 240.

Falcone, P. M., and Hiete, M. (2019). Exploring green and sustainable chemistry in the context of sustainability transition: the role of visions and policy. Current Opin. Green Sustain. Chem. 19, 66-75. doi:10.1016/j.cogsc.2019.08.002

Fernández-Dacosta, C., Van Der Spek, M., Hung, C. R., Oregionni, G. D., Skagestad, R., Parihar, P., et al. (2017). Prospective techno-economic and environmental assessment of carbon capture at a refinery and $\mathrm{CO} 2$ utilisation in polyol synthesis. J. CO2 Util. 21, 405-422. doi:10.1016/j.jcou. 2017.08.005

Haerens, J. (2017). The breakthrough of CCS/CCU: an analysis of drivers and hurdles. Master thesis. Ghent: Ghent University. 
Haarstad, H., and Rusten, G. (2017). The challenges of greening energy: policy/ industry dissonance at the Mongstad refinery, Norway. Env. Plan. C Gov. Pol. 34(2), 340-355. doi:10.1177\%2F0263774X15614660

Jones, C. R., Olfe-Kräutlein, B., Naims, H., and Armstrong, K. (2017). The social acceptance of carbon dioxide utilisation: a review and research agenda. $F$. Energy Res. 5, 11. doi:10.3389/fenrg.2017.00011

Klitkou, A., and Kaloudis, A. (2007). Scientific versus economic specialisation of business R\&D-the case of Norway. Res. Eval. 16 (4), 283-298. doi:10.3152/ $095820207 X 259308$

Kwon, Y. H., Park, J. J., Housel, L. M., Minnici, K., Zhang, G., Lee, S. R., et al. (2018b). Carbon nanotube web with carboxylated polythiophene "assist" for high-performance battery electrodes. ACS Nano. 12 (4), 3126-3139. doi:10. 1021/acsnano.7b08918

Liao, J., and Welsch, H. (2003). Social capital and entrepreneurial growth aspiration: a comparison of technology-and non-technology-based nascent entrepreneurs. J. High Technol. Manag. Res. 14 (1), 149-170. doi:10.1016/ S1047-8310(03)00009-9

North, M., and Styring, P. (2015). Perspectives and visions on CO2 capture and utilisation. Faraday Discuss 183, 489-502. doi:10.1039/c5fd90077h

O'Cass, A., and Sok, P. (2014). The role of intellectual resources, product innovation capability, reputational resources and marketing capability combinations in firm growth. Int. Small Bus. J. 32 (8), 996-1018. doi:10. $1177 / 0266242613480225$

Pathak, S., and Muralidharan, E. (2016). Informal institutions and their comparative influences on social and commercial entrepreneurship: the role of in-group collectivism and interpersonal trust. J. Small Bus. Manag. 54 (Suppl. 1), 168-188. doi:10.1111/jsbm.12289

Patricio, J., Angelis-Dimakis, A., Castillo-Castillo, A., Kalmykova, Y., and Rosado, L. (2017). Method to identify opportunities for CCU at regional level: matching sources and receivers. J. CO2 Util. 22, 330-345. doi:10.1016/j.jcou.2017.10.009

Rasmussen, E., and Sørheim, R. (2012). How governments seek to bridge the financing gap for university spin-offs: proof-of-concept, pre-seed, and seed funding. Technol. Anal. Strat. Manag. 24 (7), 663-678. doi:10.1080/09537325. 2012.705119

Reichmanis, Y. H., Minnici, K., Park, J. J., Lee, S. R., Zhang, G., Takeuchi, E. S., et al. (2018a). SWNT anchored with carboxylated polythiophene "links" on highcapacity Li-ion battery anode materials. J. Am. Chem. Soc. 140 (17), 5666-5669. doi: $10.1021 /$ jacs.8b00693

Selig, G. (2014). "Critical success factors for winning entrepreneurs and the role of an incubator in accelerating the growth of start-ups and early stage companies," in Proceedings of the 2014 zone 1 conference of the. American society for engineering education, Bridgeport, CT, April 3-5, 2014 (New York: IEEE), 1-6.

Shi, Y., Zhang, J., Bruck, A. M., Zhang, Y., Li, J., Stach, E. A., et al. (2017). A tunable 3D nanostructured conductive gel framework electrode for high-performance lithium ion batteries. Adv. Mater Weinheim. 29 (22), 1603922. doi:10.1002/adma.201603922

Stephens, J. C., and Scott, J. (2010). Assessing innovation in emerging energy technologies: socio-technical dynamics of carbon capture and storage (CCS) and enhanced geothermal systems (EGS) in the USA. Energy Pol. 38 (4), 2020-2031. doi:10.1016/j.enpol.2009.12.003

Trevor-Roberts, E. (2006). Are you sure? The role of uncertainty in career. J. Employ. Counsel. 43 (3), 98-116. doi:10.1002/j.2161-1920.2006.tb00010.x

Conflict of Interest: JS was employed by the company Bergen Carbon Solutions.

The remaining author declares that the research was conducted in the absence of any commercial or financial relationships that could be construed as a potential conflict of interest.

Copyright $(2021$ Sareen and Sagmo. This is an open-access article distributed under the terms of the Creative Commons Attribution License (CC BY). The use, distribution or reproduction in other forums is permitted, provided the original author(s) and the copyright owner(s) are credited and that the original publication in this journal is cited, in accordance with accepted academic practice. No use, distribution or reproduction is permitted which does not comply with these terms. 